\title{
LEYENDO OBLICUAMENTE: CONTRAPUNTOS REFLEXIVOS DE LA LITERATURA LATINOAMERICANA EN LA OBRA CRÍTICA DE ENRIQUE VILA-MATAS
}

\author{
(NOT SO) OUT OF HERE: REFLEXIVE COUNTERPOINTS IN \\ LATIN AMERICAN LITERATURE IN ENRIQUE VILA-MATAS' ESSAYS.
}

Felipe A. Ríos Baeza

Universidad Anáhuac Querétaro

feliperios.ffyl@gmail.com

\begin{abstract}
RESUMEN: Este ensayo se propone analizar, revisando una porción importante de los ensayos críticos que van desde El viajero más lento (1992) hasta Aunque no entendamos nada (2003), pasando por Para acabar con los números redondos (1997) y Desde la ciudad nerviosa (2000), la forma en que la literatura latinoamericana es asumida por Enrique Vila-Matas (Barcelona, 1948) con el fin de sistematizar usos y costumbres narrativos que el autor catalán emplea, luego, en su propia obra. De entrada, es posible afirmar, primero, que la literatura latinoamericana es importante en su narrativa porque se ofrece como contrapeso a otras literaturas convocadas (la centroeuropea, la francesa, la anglosajona, etc.); segundo, puede asegurarse que le permite cristalizar la manera en que opera la metaficción y la autoconciencia en sus páginas; y tercero, que con ella logra establecer definitivamente su "lugar solitario" dentro de las letras españolas, asunto que entre la década de 1970 y 1990 se había planteado más como voluntad e ideario que como elemento realmente constitutivo de su obra. Aquello se solidificará en el momento en que se aferre a los descubrimientos transatlánticos que haga como ávido lector.
\end{abstract}

PALABRAS CLAVE: Enrique Vila-Matas; literatura latinoamericana; estudios transatlánticos; arte poética; ensayo literario

ABSTRACT: This essay reviews an important part of critical essays like El viajero más lento (1992), Aunque no entendamos nada (1997), Para acabar con los números redondos (1997) and Desde la ciudad nerviosa (2000), to analyze the way in which Latin American Literature is assumed by Enrique Vila-Matas (Barcelona, 1948), with the objective of systematizing the narrative ways and customs used by the Catalan author, which he would later apply in his own work. To start, it 
is possible to assure that Latin American Literature is important in his narrative because it is offered as counterweight to other literatures mentioned (Central European, French, Anglosaxon, etc.); second, it can be assured that it allows him to crystalize the way in which metafiction and self conscience function in his own pages; and, third, that he definitely establishes his "solitary place" within Spanish literature, which was his intention and ideal during the decades between 1970 and 1990, but wasn't really a constituent element in his work. This would be fixed into his work once he had a grasp of the transatlantic discoveries he made as an avid reader.

KEYWords: Enrique Vila-Matas; Latin American Literature; Transatlantic Studies; Poetic Art; Literary Essay

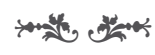

En 1973, un Enrique Vila-Matas de tan solo 25 años visita Varsovia. Tiene lecturas extravagantes a cuestas y unas ganas enormes de desmarcarse de la literatura que se produce en su país. Allí conoce al agregado cultural de México en Polonia, un escritor de cuarenta años llamado Sergio Pitol. "[E]n España", le dice luego Vila-Matas a André Gabastou, "ningún escritor de su categoría me concedía un minuto ni me dedicaba tiempo para hablar de literatura [...]. Pitol fue muy importante en aquel momento, y lo siguió siendo después. De hecho, hoy lo veo con toda claridad: Fui a Varsovia inocentemente y me convertí a escritor gracias a Pitol..." (Vila-Matas en Gabastou 2013: 98).

En un emotivo texto llamado "Sergio Pitol, mi maestro", aquello se confirma con creces: "Leyéndole, se tiene la impresión -que me ha perseguido siempre porque a fin de cuentas es mi maestro y lo es por motivos muy altos- de estar ante el mejor escritor en lengua española de nuestro tiempo. Y a quien ahora se pregunte por su estilo, le diré que consiste en huir de esas personas tan terribles que están llenas de certezas. Su estilo es contarlo todo, pero no resolver el misterio. Su estilo es distorsionar lo que mira" (Vila-Matas 2017).

Casi cuarenta y cinco años después, la obra de Vila-Matas ya ha definido sus contornos estéticos y sus líneas argumentales más visibles, pero todo parece haber arrancado allí, a comienzos de los años 70, en las conversaciones de sobremesa con un latinoamericano que fraguaba, para su propia obra, características que luego se emparentarán con los textos del propio Vila-Matas, sobre todo cuando Pitol cristalice su propuesta en su célebre El arte de la fuga, de 1996. En las obras publicadas a partir del cambio de milenio (la llamada "tetralogía metaliteraria", que incluye Bartleby y compañía, El mal de Montano, París no se acaba nunca y Doctor Pasavento), se descubre, por ejemplo, un nivel de su ars poética que lo hermana con Pitol: el motor de su creación estriba en avanzar siempre hacia adelante: 
[C]uando publiqué Bartleby y compañía me dijeron que había llegado a un callejón sin salida. Porque ¿qué pensaba escribir después de haber reflexionado sobre la lucidez de los que dejan de escribir? Para poder continuar tuve que irme al otro extremo del bartlebysmo, me fui al mal de Montano, al mal de los que no pueden dejar de escribir. Pero, cuando publiqué este nuevo libro, me dijeron que de nuevo estaba en un callejón sin salida y me preguntaban qué haría después de aquello. Escribí entonces mis memorias de juventud en París (París no se acaba nunca) y luego narré en Doctor Pasavento la desaparición a través de la propia escritura [...]. Como me había plantado ante el abismo mismo, decidí que para continuar sólo tenía que hacer lo que en definitiva ya había hecho en los tres anteriores libros: seguir jugándomela, dar un paso más adelante, aunque en este caso el paso sería en el vacío [...]. Entonces, lo que hice fue instalarme en un espacio de exploración del vacío, del abismo. (VilaMatas en Gabastou 2013: 176)

La conexión, primero subterránea y luego evidente, entre Vila-Matas y Sergio Pitol hace pensar en otros vínculos con escritores latinoamericanos contemporáneos o anteriores: Roberto Bolaño, Rodrigo Fresán, Juan Villoro y, por supuesto, César Aira, un autor muy próximo ante todo en su honda conciencia metaliteraria al abordar el trabajo de escritura y en sus contextos de recepción crítica. ${ }^{1}$ En uno de sus más célebres libros, El congreso de literatura, Aira escribe algo que parece no solo definir su poética, sino la de su oscuro hermano gemelo catalán: "En mi caso, nada vuelve atrás, todo corre hacia adelante, empujado salvajemente por lo que sigue entrando por la válvula maldita [...]. El camino no es otro que la harto trillada (por mí) 'huida hacia adelante'. Ya que la vuelta atrás me está vedada, jadelante! ¡Hasta el final! Corriendo, volando, deslizándome, a agotar todas las posibilidades, a conquistar la serenidad con el fragor de las batallas. El vehículo es el lenguaje. ¿Qué otro?" (Aira 2009: 30).

"En el libro que terminé ayer", se lee en el cuento "Café Kubista", de Exploradores del abismo (2007), "todos los personajes acaban siendo exploradores del abismo o, mejor dicho, del contenido de ese abismo. Investigan la nada y no cesan hasta dar con uno de sus posibles contenidos, pues sin duda les disgustaría ser confundidos con nihilistas [...]. Y no hay duda de que conectan con una frase de Kafka: 'Fuera de aquí, tal es mi meta'" (Vila-Matas 2007: 9). "Fuera de aquí, tal es mi meta" es una cita apropiada que parece definir el visible proyecto vilamatasiano; pero existe otro, más secreto, menos desenfrenado, que aparece

\footnotetext{
${ }^{1}$ Este fenómeno es singularísimo y define en parte la situación -explícita en lo referencial, subterránea en lo metaliterario- de Vila-Matas como el más "latinoamericano" de los autores españoles. Al respecto, son singulares las palabras que Margarita Heredia escribe en el prólogo al compilado crítico Vila-Matas portátil. Un escritor ante la crítica: "En 1994 preparaba una tesis de licenciatura sobre Vila-Matas para la Universidad Nacional Autónoma de México. Para entonces, el escritor catalán ya había sido leído con fortuna por autores latinoamericanos como Álvaro Mutis, Augusto Monterroso y Sergio Pitol, y los jóvenes críticos mexicanos comenzaban a verlo como un significativo renovador de la literatura española [...]. En cierta forma, se trataba de un autor con un recorrido crítico más amplio en América Latina que en su país" (Heredia 2007: 9). De esto da cuenta el propio compilado de Heredia, que tiene a críticos y escritores "del lado de acá" -Álvaro Enrigue, Christopher Domínguez Michael, Roberto Bolaño y Daniel Sada, entre otros- como los primeros en evidenciar la propuesta que, con tintes latinoamericanos, un escritor "del lado de allá" ya estaba articulando desde comienzos de los 90.
} 
por debajo de esa fuga hacia adelante y que está contrapunteado, creo, por sus profundas y hasta ese momento secretas lecturas latinoamericanas. Repasando con mayor detención su declaración a Gabastou, si en el 2000 había publicado una novela sobre la imposibilidad de la escritura (Bartleby y compañía), en el 2002 aquello se volverá un juego metaliterario, espeleológico, que le permitirá escribir un libro sobre los que asumen compulsivamente la literatura (El mal de Montano). Asimismo, esta idea de la enfermedad literaria le dará pie, un año después, para aventurarse con un proyecto que desfigurará la frontera entre memoria e invención (París no se acaba nunca); proyecto que luego, en 2005 con Doctor Pasavento, tenderá a desvanecerse, borrando el eje donde el anterior libro pivotaba, es decir la figura del "autor". Ya desaparecido el autor, ¿qué queda? El abismo. Es entonces cuando prueba a hurgar qué hay en ese vacío y ese silencio, en 2007, con Exploradores del abismo, antes de que sus intereses como escritor se enfoquen en otros abismos. ${ }^{2}$

Ese nivel visible de creación literaria -la fuga creativa hacia adelante- se acompaña también de un movimiento proyectivo de sus referentes, que van, primero, de los escritores y artistas franceses (Valery Larbaud, Maurice Blanchot, Marcel Duchamp, Stéphane Mallarmé) a los centroeuropeos (Robert Walser, Franz Kafka, Witold Gombrowicz), para luego instalarse, a partir de Ella era Hemingway. No soy Auster (2008) y Dublinesca (2010), en una serie de referentes anglosajones (James Joyce, Samuel Beckett, Ernest Hemingway y el mencionado Paul Auster). No obstante, existe una corriente subterránea, un nivel más hondo en su obra que, como se descubrirá en este trabajo, no se comporta de manera proyectiva, sino recursiva. Al menos desde Lejos de Veracruz (1995), en su literatura se reconocen dos movimientos: ese que se dispara hacia el futuro y que parece conectar temática y estéticamente un libro con el siguiente; y otro que a pesar de todo permanece, que se halla en los núcleos recónditos de cada libro y que no avanza, sino que se retrotrae, espejea y le permite hacer reflexión de su singular propuesta. Ese "río profundo" es justo el que conecta al catalán con los nombrados Aira, Bolaño y Pitol, pero también con Augusto Monterroso, Jorge Luis Borges, Juan Rulfo y Adolfo Bioy Casares, entre otros.

De esta manera, en el presente ensayo propongo analizar, revisando una porción importante de sus ensayos críticos, el modo en que la literatura latinoamericana es asumida por Enrique Vila-Matas con el fin de sistematizar usos y costumbres narrativos que empleará, luego, en su propia obra. De entrada podemos afirmar varias cosas: primero, que la literatura latinoamericana es importante en su poética porque se ofrece como contrapeso a otras literaturas convocadas; segundo, que dicho bagaje le ayudará a cristalizar la forma en que opera la metaficción y autoconciencia en sus páginas; y tercero, que aquellos

\footnotetext{
2 "[E]n algunas temporadas viví atrapado por la literatura", se lee en el prólogo de En un lugar solitario. Narrativa 1973-1984 (2011). "En esos días busqué llevar mi poética, libro a libro, sistemáticamente, a un callejón sin salida, con la idea de ser un héroe y demostrar, una vez tras otra, que sabía salir indemne de las trabas que yo mismo me creaba, que sabía superar todos los obstáculos que yo mismo levantaba para no tener más remedio que caer en mi propia trampa y no poder continuar y tener que caer en un silencio profundo y definitivo..." (Vila-Matas 2011: 23).
} 
autores convocados y sus libros le permitirán establecer definitivamente su "lugar solitario" dentro de las letras españolas, ${ }^{3}$ asunto que entre la década de 1970 y 1990 se había planteado más como voluntad e ideario que como elemento realmente constitutivo de su obra. Aquello se solidificará en el momento en que se aferre a los descubrimientos transatlánticos que poco a poco, y gracias a los propios sellos editoriales donde empezará a publicar (Anagrama, sobre todo), el autor irá haciendo.

\section{LEYENDO LATINOAMÉRICA DE PASADA}

Hay una característica notoria en sus textos, y es que, en comparación con los referentes europeos y norteamericanos mencionados, Vila-Matas lee Latinoamérica siempre tangencialmente. En esa tangencialidad, en ese no asumir directamente sus propuestas ni temáticas, es donde se extrae parte de la poética que, aventuramos, se cristaliza a partir de Bartleby y compañía. Los libros que cubren buena parte de la década de 1980 y 1990 (Una casa para siempre, Hijos sin hijos y Suicidios ejemplares, sobre todo) se caracterizaban por una estructura base: instalar una temática lo suficientemente potente en el corazón mismo del libro (la modulación de registros, la negación de la paternidad, la muerte por mano propia) y hacer girar los cuentos alrededor de ella, cumpliendo estos volúmenes con lo que, en La unidad y la diversidad. Teoría e historia de las colecciones de relatos integrados, el crítico José Sánchez Carbó ha calificado como "colección de

\footnotetext{
3 Este punto es profusamente explicado en el prólogo de En un lugar solitario. Narrativa $1973-$ 1984, volumen de 2011 que recoge sus cuatro primeros libros. Desde el célebre colmado en Melilla, mientras hacía su servicio militar, "[e]nvié una carta a una amiga [...] y le pedí que me enviara libros que acabaran de publicar narradores o cuentistas españoles, preferentemente de mi generación. De algunos había ya oído hablar, e incluso con más de uno me había cruzado en bares nocturnos de mi ciudad. Se trataba de leer lo que hacían para hacer algo parecido, aunque distinto, quizá para hacer todo lo contrario de lo que ellos hicieran [...]. A la hora de escribir, deseaba ser muy distinto a todo el mundo, no parecerme a nadie, seguir un camino solitario y único" (Vila-Matas 2011: 16-20). Sobre este gesto singular, donde evidentemente hay una "toma de posición", en palabras de Pierre Bordieu, puede revisarse el ensayo de Alejandro Palma, Alicia Ramírez y Felipe Ríos, "Enrique Vila-Matas, autor de la obra de Enrique Vila-Matas": "Enrique Vila-Matas es un escritor que ha forjado su figura de autor a través de ciertas tomas de posición en el campo literario. Específicamente, en 2011 publica En un lugar solitario. Narrativa 1973-1984, donde lo más interesante es la inclusión de un largo prólogo en el cual se da a la tarea de organizar sus primeros trabajos narrativos y tomar ciertas decisiones que pudieran interpretarse como la voz del autor fijando las directrices del inmediato porvenir de su obra. Teniendo en cuenta los trabajos de Pierre Bourdieu sobre el funcionamiento del campo cultural y haciendo uso de algunos de sus conceptos, nos parece que Vila-Matas ha reconstruido varios hechos de su vida literaria en la guía que escribe para los lectores de su narrativa inicial. La manera en que este narrador catalán ha reconstruido su imagen de autor para esta segunda década del siglo XXI remite a la discusión que a finales de los sesenta sostuvieron Roland Barthes, Michel Foucault y otros autores respecto de la noción de autor, de escritor y de obra en el marco del pensamiento posestructuralista. Bajo dicho marco es que podemos dimensionar la importancia de este momento en la carrera de Enrique Vila-Matas para sugerir una nueva orientación como autor popular. Por otro lado, hacemos patente una línea de escritura en la narrativa hispanoamericana contemporánea, de la que Vila-Matas parece ser uno de sus más altos representantes, donde la ficción se convierte en una profunda realidad. Bajo estas ideas se pudiera pensar que el escritor catalán va ejecutando una variante del célebre cuento de Jorge Luis Borges: 'Pierre Menard, autor del Quijote', en el sentido en que cabe la posibilidad de que Vila-Matas, a partir de sus variados proyectos de reescritura, se convierta en autor de la obra de Vila-Matas" (Palma et. al 2013: 443-444).
} 
relatos integrados": "[U]na modelización literaria caracterizada porque un autor reúne y organiza en un libro una serie de textos autosuficientes que, relacionados hipotáctica o paratácticamente, configuran, con la colaboración del lector, un todo coherente y permiten un orden de lectura sucesivo o salteado" (Sánchez Carbó 2012: 46).

A partir de 1997, con Extraña forma de vida, Vila-Matas continúa un trabajo no solo de apropiación textual, configurando un "canon de deseo", al decir de Borges, con el que quiere ser fuertemente vinculado -Kafka, Walser, Pessoa, Duchamp, Jarry, Gombrowicz, etcétera-, sino una labor de apropiación vital: se sabe que en ese libro no solo se cruzan referencias a la poesía de Álvaro de Campos y al Libro del desasosiego, de Bernardo Soares, sino a episodios significativos de la vida del propio Fernando Pessoa. Esa fabulación portuguesa será llevada al extremo en El viaje vertical (1999) -novela aparentemente realista, pero donde hay un protagonismo decidor de los espacios en los que, cual Altazor de Huidobro, el septuagenario Federico Mayol va cayendo: Azores, Madeira, Lisboa y Cabo Verde ${ }^{4}-$ y en "Mastroianni-sur-Mer" -una conferencia incluida, después, en Desde la ciudad nerviosa (2000) a la que se le ha puesto poca atención pero que representa, a nuestro parecer, un punto de inflexión decisivo en su literatura-. "Mastroianni-sur-Mer" nace de una charla que Vila-Matas debía dar, por encargo, en un ciclo que exploraría las relaciones entre cine y literatura. En ese momento, para salir del paso, el autor le soltó a su interlocutor, casi sin pensar, el nombre de la película que deseaba analizar (Sostiene Pereira, de Roberto Faenza) y el nombre de la futura charla (Narración y toma de conciencia). Como trabajaba paralelamente en El viaje vertical, dicho encargo le provocó enormes dificultades: "No hacía más que pasarlo mal todo el rato. Estaba trabajando en las últimas páginas de El viaje vertical -y por tanto no me dedicaba a preparar nada de Narración y toma de conciencia-, pero también es cierto que a todas horas no hacía más que recordar -como un peso terrible que llevara en el fondo de mi alma -que el 28 de enero podía ser mi perdición" (Vila-Matas 2000a: 175). Como le confesará al poeta y conductor chileno Cristián Warnken en el desaparecido programa de televisión La belleza de pensar, con el tiempo encima se entregó a la escritura automática. Y lo que salió de allí fue un texto fragmentario, caracterizado por la asociación de elementos agrupados entre sí para buscar una sola cosa: el origen de su vocación literaria. Se trata de un texto que comienza

\footnotetext{
${ }^{4}$ El descubrimiento de estos entresijos más allá del realismo se debe, en buena parte, a la lectura que tanto Sergio Pitol como Rodrigo Fresán Ilevaron a cabo de El viaje vertical desde América Latina. Mientras el mexicano comentó que era "una novela a primera vista convencional pero que a partir de un momento demostraría ser todo lo contrario. Es su libro más enigmático; una historia de equivocaciones, aunque no sepamos exactamente cuáles. Cada vez que se acerca al realismo tenemos la sensación de que su autor juega con dinamita. El final se pierde en una neblina meramente conjetural. Es una novela de educación, a pesar de que el septuagenario protagonista tiene una edad poco apropiada para ello. Como siempre, en el cuerpo de la escritura hay un diálogo entre el ensayo y la ficción, una reflexión sobre la literatura y también la comparación entre ella y el desconcierto general que es la vida" (Pitol 2007: 175); el argentino señaló: "Vila-Matas es el segundo español que gana este premio de diseño latinoamericano (el Rómulo Gallegos, en 2001). El otro fue Javier Marías. El último fue el chileno Roberto Bolaño. Todos ellos unidos por el signo de una literatura mixta, mestiza, donde los límites se confunden y la crónica puede bailar con lo ficticio sin pisarle los pies" (Fresán 2007: 166).
} 
de manera muy controlada, refiriendo su deseo de ser escritor para parecerse a Giovanni Pontano, el personaje de Marcello Mastroianni en La notte (1961), de Michelangelo Antonioni, y acaba, 22 fragmentos después -es decir, luego de un exceso de entropía literaria- en un destino inesperado: el faro de Cascais, cerca de Santa Martha, que Vila-Matas dice haber conocido únicamente por una fotografía de la revista Vogue. "Uno siente la memoria difusa de haber estado alguna vez en un lugar", concluye. "¿Cuándo? No sabemos. Pero ya habíamos estado ahí antes de haber venido nunca" (2000a: 204).

Ambos textos de 1999 nos parecen decisivos, pues de ahí en adelante Vila-Matas asumirá para sus libros la idea del "viaje vertical" no como una trama, sino como un procedimiento creativo y una estructura posible para sus volúmenes, hallando sus temas bajo los principios de "no retorno", de El viaje vertical, y de escritura automática, empleado en "Mastroianni-sur-mer". Sus novelas, libros de relatos, colecciones de ensayos e incluso el Dietario voluble se engarzarán con esta lógica: intentarán parecerse a esos libros, como Hijos sin hijos o Suicidios ejemplares - un tema aparentemente dominante alrededor del cual giran las historias- pero encadenarán asociativamente la vida y los textos de otros, y la vida y los textos propios, con el fin primario de ir hacia adelante. En ese riesgo, lo que los sujeta y les permite ciertos intervalos reflexivos serán algunas vidas y obras de algunos autores latinoamericanos. Al tratarse de un bagaje bibliográfico más profundo, menos visible, se entiende por qué se presenta de forma oblicua, así como decía Harold Bloom que se formulaban los monólogos de Hamlet, ${ }^{5}$ y que el mismo Vila-Matas, en esa entrevista con Warnken, refiere: para oírse a sí mismo de pasada (Vila-Matas en Warnken 2002).

Aunque esto se establece como procedimiento consciente para su ficción a partir de Bartleby y compañía, tiene como antecedente directo esos libros de ensayos, verdaderos campos de experimentación que ha venido publicando desde principios de los '90. Ya el propio escritor mexicano Daniel Sada señalaba, en 1993 y desde la revista Vuelta, que ese modo tangencial de leer a varios autores, pero sobre todo a los latinoamericanos, le permitió a Vila-Matas configurar su poética por venir. Según Sada, en El viajero más lento los autores reseñados "se presentarían como exégetas, antes que asumirse descaradamente como creadores. Para Vila-Matas este concepto es indiscernible, pero también advierte que a partir de la exégesis abundan los resquicios, las tramas escurridizas, los resúmenes equívocos [...]. Si en la literatura no hay nada nuevo, salvo lo que se ha olvidado, no está mal que de cuando en cuando [...] se repitan las mismas historias" (Sada 2007: 95). No por nada, un volumen menor, publicado en Mérida, Venezuela, lleva por título Extrañas notas de laboratorio.

\footnotetext{
5 "Como he apuntado ya, en Shakespeare la conciencia extraordinaria descuella en la facultad de oírse a sí mismo, por así decirlo, sin quererlo: tales los casos de Hamlet, Yago, Cleopatra o Próspero. [Emily] Dickinson mantiene este atributo, pero con frecuencia [Walt] Whitman intenta ir más allá. El choque de oírse a uno mismo consiste en que uno captura una inesperada otredad" (Bloom 2002: 95).
} 


\section{BIOY Y BORGES: IDENTIDAD Y DESAPARICIÓN}

En El viajero más lento, entre tanta crónica europea cargada de fascinación por la literatura y el paisaje alemanes ("El otro Frankfurt", "Alemania en otoño") y por la literatura y el paisaje franceses ("De Perec al infinito", "La lengua rota de Céline"), aparecen dos textos que provocan un quiebre interesante en la compilación: "Bioyinventario" (publicado originalmente en 1990, en Diario 16) y "¿Existe realmente Borges?" (aparecido en La Vanguardia, en 1982). En el primero, lo más extravagante es el formato: una crónica sobre la obra de Adolfo Bioy Casares que emplea el abecedario, y cuyo contenido parece distanciarse deliberadamente del acostumbrado texto vilamatasiano, armado, como se sabe, con asociaciones a libros, películas, canciones y anécdotas, oportunas pero a la vez personalísimas. Estamos delante, tal vez, de su texto más académico (sin caer en los insufribles clichés de los que pecan estos textos), donde hay un despliegue asombroso de conocimientos sobre la obra del autor argentino. A lo largo de este $A B C$, Vila-Matas parece poner a distancia a Bioy para subrayar aquellos aspectos que vuelven significativa su obra-la fantasmagoría, la imposibilidad del amor-, con una retórica que, insistimos, no parece la propia: "En un relato de juventud, Los novios en tarjetas postales, un joven interpola su imagen en la fotografía de la muchacha que ama. Preludia el amor entre la imagen fantasmal de Faustine y el protagonista de La invención de Morel" (Vila-Matas 2001: 55); "Estamos inmersos ya en el inconfundible clima de El sueño de los héroes y en las tres noches de carnaval de 1927, cuando se dan las condiciones de borrachera, locura e irresponsabilidad para que Gauna, el protagonista, sueñe con unos héroes" (2001: 60), etcétera. Hay, pues, un distanciamiento inhabitual entre el objeto referido y sus propias circunstancias de vida; excepto al final, donde se permite decir, haciéndose eco de una declaración de Bioy, que él también ha estado enamorado de Clara, el personaje de El sueño de los héroes. Aventuramos la concreción de la tesis planteada más arriba: leer a Bioy, más que permitirle un engarce de temas para ir hacia adelante y así desmarcarse rápidamente de sus contemporáneos españoles -un avance trepidante, de una cita a otra, para alcanzar, en suma, "el lugar solitario"-, lo que vemos es una dilación necesaria, un retraso en la concreción de ese proyecto vertiginoso que se ha planteado, sobre todo cuando en la entrada llamada, justamente, "Identidad" -muy significativa: recordemos que pocos años antes de esta crónica, Vila-Matas ha publicado Impostura y Una casa para siempre- cite sin aludir a su fuente ${ }^{6}$ unas palabras que Bioy Casares pronunció en un taller literario: "Somos demasiado parecidos a nosotros mismos; el riesgo es parecernos demasiado. Cuando yo era chico tenía la esperanza -contra todo lo que podía esperarse- de ser varias personas. Ser una sola persona me parecía muy poco. A medida que uno vive, progresivamente se afianza el mismo maniático, el mismo nimio personaje" (Bioy en Vila Matas 2001: 56). Podría haber resultado casi un epígrafe para esos textos de ficción publica-

\footnotetext{
${ }^{6}$ Esta conversación está incluida en el libro Adolfo Bioy Casares. Sobre la escritura: conversaciones en el taller literario, de Félix Della Paolera y Esther Cross (2007: 38-39).
} 
dos en 1984 y 1988. "Escribimos siempre después de otros", dirá Vila-Matas en su artículo "Intertextualidad y metaliteratura", "[y] a mí no me causa problema recordar frecuentemente esta evidencia. Es más, me gusta hacerlo, porque en mí anida un declarado deseo de no ser nunca únicamente yo mismo, sino también ser descaradamente los otros" (Vila-Matas en Gabastou 2013: 125).

El texto siguiente de El viajero más lento, "¿Existe realmente Borges?", es aún más impactante. Escrito entre la redacción de Nunca voy al cine e Impostura (volumen de cuentos, el primero; y novela, la segunda, donde es visible la apuesta por una narración algo extravagante, pero causal), el de Borges representa un texto aún embrionario pero significativo del modo en que la literatura latinoamericana fecundará y operará en sus textos. El cuento comentado es "La biblioteca de Babel" y aquí el tono de Vila-Matas es, otra vez, el del ensayista erudito y asombrado. Allí cuenta las aproximaciones históricas a dicho relato, sorprendido de que este relato haya hecho el salto de la crítica literaria (Julio Ortega, Umberto Eco) al de las ciencias exactas (Lucio Lomardo Radice, Tullio Regge, George Lutli) para afirmar con propiedad que el cuento de Borges, cuando no imposible, implica la consabida sensación kafkiana de un sistema mayor anulando la individualidad del sujeto.

Este texto comprende dos asuntos importantes: de entrada, la fascinación de cualquier lector metaliterario, aunque primigenio, por la idea de la biblioteca infinita y la posibilidad de contener todos esos textos para usarlos a antojo; pero, al mismo tiempo, el terror de perder la identidad en ellos, simbolizado por la tan temida caída en el foso hexagonal. Por eso, en estos primeros libros Vila-Matas combatirá el terror de esa anulación trabajando una autoficción muy férrea, blindada por todos los flancos. Ya sea por la creación de un personaje que, a la vez, es sujeto de la enunciación (Una casa para siempre, Lejos de Veracruz) o bien la edificación de un "personaje-escritor" que funciona, también, como hilo conductor del argumento (París no se acaba nunca, Extraña forma de vida), no será hasta el Doctor Pasavento, en 2005, que Vila-Matas se plantee un coqueteo mayor con la desaparición del autor, con su disolución. Como puede rápidamente evidenciarse, dicha desaparición no es total: se trata más bien, entre Pasaventos, Ingravallos y Emmanuel Boves, de transfiguraciones de identidad (asunto que ya se anunciaba en Bartleby y compañía con Marcelo, el narrador, cuando cambia su nombre primero a CasiWatt y luego a Scapolo), hasta llegar solamente a un leve anonimato; un baile de máscaras para alcanzar cierto silencio: el talud del cual saldrá fragmentado en 2007, con el libro de cuentos Exploradores del abismo.

No es menor este temprano influjo borgesiano: por un lado, está el privilegio de tener un carné de socio exclusivo de la biblioteca de Babel; pero, por otro lado, sale a la superficie un pavor real al no poder recrearse en dicha biblioteca, debido a que la estructura y operatividad misma del recinto condenan a todo bibliotecario a su desaparición.?

\footnotetext{
7 Bien lo señala Álvaro Enrigue: "Cuando un lector está leyendo a Vila-Matas, siempre está frente a dos libros: el que tiene en las manos y el que Vila-Matas leyó mientras estaba escribiendo. En ese sentido, es borgesiano: el autor que se juega su biblioteca mientras escribe. $\mathrm{O}$ el autor que juega el juego de las influencias como un póquer abierto [...]. Siempre hay un libro presente y uno anterior. Y el libro anterior no funciona como una fuente, sino como un talismán" (Enrigue 2012: 34).
} 


\section{Monterroso: Desplazamientos narrativos}

Del mismo modo ocurre en Para acabar con los números redondos, libro de 1997 que recoge las crónicas literarias que Vila-Matas escribiera para el Diario 16, de Madrid, incluso luego que este desapareciera. Entre Nabokov, Chéjov, Baroja, Joyce y Marguerite Duras, destacan algunos retratos singulares: Augusto Monterroso, Octavio Paz, Macedonio Fernández y, otra vez, Jorge Luis Borges. Como pasa con varios de los referentes que okupa, cual anarquista en una casa aparentemente vacía, ${ }^{8}$ hablar de Paz le ayuda a detallar conscientemente asuntos de su itinerario como escritor: " "Ese poema [El descenso, de William Carlos Williams] me inspiró mi novela Lejos de Veracruz. Mientras Octavio Paz leía yo iba leyendo en mi mente toda mi futura novela" (Vila-Matas 1997: 74). Del mismo modo, hablar de Macedonio le servirá como adelanto de la forma en que moldeará el bartlebysmo a partir del 2000: "Tenía este hombre [...] cierta 'incapacidad' para escribir, lo que no significaba que no tomara la pluma de vez en cuando: 'No leer es como un mutismo pasivo, escribir es el verdadero modo de no leer y de vengarse de haberse leído tanto'" (1997: 90). Pero es en la crónica "De un fabulista a otro", dedicada a Monterroso, donde, de manera menos consciente, explota una técnica narrativa nueva: esa estrategia de desplazamiento, de tangencialidad, descrita con anterioridad:

$[\mathrm{H}] \mathrm{e}$ despertado obsesionado con una fábula, El paraíso imperfecto, de Augusto Monterroso [...]. ¿Por qué Monterroso de pronto? Supongo que porque siempre lo he admirado [...]. Sería ideal que Monterroso hubiera nacido en un día de octubre de hace 74 años, pues así tendría ya la excusa totalmente redonda para estar hablando de él. Pero lo cierto es que no tengo ni idea del mes del año en que nació, pero sí se me ocurre un truco para poder hablar de este escritor: hablar de otro fabulista -este muy edificante-, hablar de Félix

\footnotetext{
8 Para ahondar en esta estrategia literaria, puede revisarse un ensayo de mi autoría, "Vila-Matas: ese okupa literario": "Insertándose en estilos, estructuras e historias ya descritas por otros es que Enrique Vila-Matas ha venido okupando -de un modo más deconstructivo que anarquista- un lugar en el sistema literario contemporáneo [...]. Vila-Matas, ese okupa, ese vampiro literario, ha convertido el inquietante 'síndrome de Rendfield' en un elemento constitutivo de su poética. Es decir, la convocatoria a otras voces y otros ámbitos en su espacio literario no estaría trabajada simplemente en el plano del pastiche, pues la autoparodia y las reflexiones de sus propios libros, al interior de sus propios libros, estarían proporcionando un componente alternativo a la categorización de su literatura como meramente posmoderna" (Ríos Baeza 2013: 74-91).

${ }^{9}$ Lo mismo ocurre en ensayos de otros libros, como "¿Estoy en Chile?", donde cuenta el germen de El mal de Montano -"Lo cierto es que en Chile nació Montano, el personaje de una de mis novelas, y después, directamente desde la orilla del batallador Pacífico, viajé con él a la cumbre de una montaña suiza y de ella descendí, hace solo unas semanas, hasta París, en busca de Tongoy (otro personaje de mi novela medio chilena)..." (Vila-Matas 2003: 121); y "Nuestro Emar de ultramar", donde apuntala dos temas recurrentes en la narrativa que en ese momento estaba construyendo: la identidad paradójica -"Juan Emar pronto sintió la llamada de París [...] con la idea de 'darle a mi vida un objetivo, una misión que me hará feliz y que vaya con mi temperamento'. Y añadía: 'Chile, a mi vuelta recibirás y mantendrás al nuevo y verdadero yo'. ¿De qué nuevo yo hablaba?" (2003: 133) - y la difuminación de fronteras entre realidad y ficción -“Me propongo hablar de él un mediodía al año como mínimo, todos los años. Y no hacerlo nunca en Chile, donde ya lo conocen (o deberían conocerlo), sino en lugares donde no han oído hablar nunca de él y creen que yo me invento su biografía. Que es lo que en realidad hago, aunque Emar existe" (2003: 136-137).
} 
María de Samaniego, nacido en la Rioja alavesa, en el pueblo de Laguardia, un doce de octubre del año 1745. (Vila-Matas 1997: 21)

Plantear denotativamente un argumento para, connotativamente, avanzar hacia otro más brumoso y atractivo -en este caso hablar de Samaniego para poder hablar de Monterroso- es uno de los procedimientos que se fraguarán cuando lea lateral u oblicuamente a escritores latinoamericanos, encontrando en la "tetralogía metaliteraria" su asidero narrativo más complejo. "[A]unque no he entendido nunca nada, yo he seguido siempre adelante buscando y encontrando siempre en la literatura, y paradójicamente en el absurdo, el sentido del mundo" (Vila-Matas 2003: 7), declara en la presentación de su libro de ensayos Aunque no entendamos nada, lo que confirmaría este punto.

No se trata solamente de dar la sensación de un work in progress, de un texto que no se planea y que se va haciendo a medida que se escribe, sino de mostrarle al lector que hay un contenido secreto, latente, del que se quiere hablar realmente pero haciéndole guiños siempre a otro. Ese contenido secreto bien puede presentarse por revelación -en El mal de Montano, por ejemplo, se construye una novela, en la primera parte; y la historia de la escritura de esa novela, en la segunda parte; para hablarnos, en una tercera parte, de lo que realmente parecer importar: el hecho de que la quintaesencia de la literatura, y de la vida por antonomasia, se encuentra en los papeles personales de un individuo, confirmado desde el título mismo de esa sección: "Diccionario del tímido amor a la vida"-; o bien por intermitencia e infiltración-entre los fragmentos que alimentan el catastro de autores del no, en Bartleby y compañía, se va colando aquello que le parece importar al narrador: la reflexión sobre un apacible estilo de vida solitario, ya sea por su propio aspecto físico ["Nunca tuve suerte con las mujeres, soporto con resignación una penosa joroba" (Vila-Matas 2000b: 11), etcétera]; ya sea porque sus relaciones son escasas, apenas con dos amigos, con los que intima por teléfono o correo -Derain, el crítico literario, y su amigo Juan, que trabaja en el aeropuerto y que afirma que, luego de Robert Musil y Felisberto Hernández (otro latinoamericano radical), no se ha escrito nada bueno en la literatura: "¿Me oyes bien? Musil y Felisberto. Después de ellos ya nadie enciende lámparas" (2000b: 79)-.

\section{BOLAÑO: CONFLICTO Y OSCILACIÓN}

Finalmente, un último procedimiento que Vila-Matas ensaya primero en sus textos de no ficción y luego en sus novelas es aquel que prueba en la crónica "Bolaño en la distancia", del volumen Desde la ciudad nerviosa, al reaccionar a un comentario de Juan Antonio Masoliver Ródenas. Masoliver afirma que, por su extravagancia, Vila-Matas sería un lector ideal para Los detectives salvajes. El barcelonés señala que puede que Masoliver "haya acertado al considerarme un lector idóneo para la novela de Bolaño [...]. Es posible incluso que sea el escritor que más se parece a mí, o viceversa" (2000a: 311). Los temas recurrentes de Bolaño -las referencias literarias, reales y apócrifas; la arriesgada apuesta de sus 
protagonistas; la atractiva estructura de sus libros; la inestabilidad perceptiva de sus personajes, etcétera- le hacen creer que ya no está en ese "lugar solitario", blindado desde hace treinta años para las amenazas de la gazmoñería y del realismo de la literatura española. Esa nivelación con el chileno lo pasma al inicio de la crónica y le permite hacer consciente algo que se planteaba al inicio de este ensayo: la conquista de su sitial en el canon pasa necesariamente por su asociación con esa literatura más allá del Atlántico. Esta cita es elocuente al respecto:

\begin{abstract}
Masoliver está haciendo un guiño a un artículo que publiqué hace unos años en la prensa madrileña y en el que me hacía eco de unas palabras de Juan Villoro, que a su vez se hacía eco de otras palabras, las del escritor argentino César Aira, que bien podría ser también un lector ideal de Bolaño. Decía yo en este artículo: "Me entero por Juan Villoro de las palabras del escritor argentino César Aira que, en una reciente entrevista, se refiere al mito literario que domina nuestro fin de siglo, el del escritor gentleman, profesional, que no confunde los libros con su persona y desdeña el carisma como prolongación de la obra. Eduardo Mendoza, Muñoz Molina, Juan José Millás y Javier Marías, por ejemplo, ilustran a la perfección entre nosotros este modelo de fin de milenio. Están alejados de Gómez de la Serna, que recitaba desde el lomo de un elefante, o de Valle-Inclán, que se quejaba de que no le permitían subir al tranvía con dos leones". (Vila-Matas 2000a: 312)
\end{abstract}

Con esto comenzamos a entender qué se halla en ese "lugar solitario" vilamatasiano, o bien cómo está amueblada esa "casa para siempre" a la que nos tiene acostumbrados como lectores: primero, con la imagen auto-edificante de un escritor en las antípodas del escritor profesional, ese que alabanciosamente asume la literatura como un trabajo de burocracia que acaba a las seis de la tarde y que no contamina su visión del mundo - por cierto, la misma pretensión de Julio Cortázar al dirigir la vista, desde la Argentina, hacia autores como Clarín, Pío Baroja y Blasco Ibáñez ${ }^{10}$. A ese tipo de escritor hay que plantarle cara con "una militancia alegre en el mundo de los escritores que no quiere tener pasaporte: artistas de alma nómada, enemigos de los viajes obligados, que no siguen más rumbo que el de su propia estrella, aunque esta sea distante como la estrella distante de Bolaño" (2000a: 313). Y segundo, con la evidencia de que, para apartar a los Muñoz Molina y los Millás que a Vila-Matas le estorban para llegar efectivamente a los Gómez de la Serna y los Valle-Inclán que le interesan, tiene que apoyarse en los varios Airas, Villoros y Bolaños que manejan un tipo de propuesta artística homogénea a la suya.

No obstante, Vila-Matas parece apreciar a Valle-Inclán y Gómez de la Serna más por su conducta extravagante que por un material literario real que haya

\footnotetext{
10 "Nosotros, a diferencia del escritor europeo que escribe con armas afiladas colectivamente por siglos de tradición intelectual, estética y literaria, estamos forzados a crearnos una lengua que primero deje atrás a Don Ramiro y otras momias de vendaje hispánico, que vuelva a descubrir el español que dio a Quevedo o Cervantes y que nos dio Martín Fierro y Recuerdos de provincia, que sepa inventar, que sepa abrir la puerta para ir a jugar" (Cortázar en Alazraki 1994: 92).
} 
fecundado sus papeles, ${ }^{11}$ lo que hace pensar que en ese primer movimiento pendular u oscilatorio -ir de las letras españolas a las latinoamericanas, para volver nuevamente a las españolas, con el fin de leerlas con mayor luminosidad- el autor gusta detenerse en el procedimiento intermedio. Esto, suponemos, a VilaMatas le causa conflicto en cierto nivel y, por lo mismo, produciría un segundo movimiento pendular. Después de reconocer su cercanía con Bolaño, Vila-Matas cambia aparente y repentinamente de opinión: “Es muy probable, por tanto, que Bolaño pertenezca a la familia literaria que reúne Italo Calvino en torno a una de sus propuestas para el próximo milenio: la de la multiplicidad. Escribo esto y respiro aliviado y me distancio un poco más de Bolaño No somos -ahora me doy cuenta- ni mucho menos tan parecidos como creía que éramos. Yo más bien soy un escritor de otra sección del libro de Calvino. Yo más bien fatigo los anaqueles de los escritores de la levedad" (2000a: 315. La cursiva es nuestra). Constatarlo le causa alivio. La pregunta es por qué. ¿Por qué parece haber un proceso metabólico casi inmediato con el diario de Kafka, los ready-made de Duchamp o los heterónimos nihilistas de Pessoa, al punto de citarlos en plena compatibilidad con su ideario literario, y en cambio con algunos textos latinoamericanos lo que se evidencia es una crisis, una contradicción, un desafío?

Esto es interesante. Vila-Matas en esta crónica estaría entregando, de manera latente y no manifiesta, una tercera forma en la cual la literatura latinoamericana afecta su condición tanto de lector como de autor. Además de representar el núcleo más soterrado de sus libros -aquel que parece no moverse cuando se "fuga hacia adelante", pues le permite poner a distancia y en perspectiva su propia retórica y temática- y de ser leída tangencial y no directamente, la tercera vía del latinoamericanismo en su obra es la resistencia a absorber, en los primeros momentos, dichos textos transatlánticos en su "lugar solitario". Leer y asimilar a los latinoamericanos le representa un esfuerzo que no pasa por lo intelectual, sino por el extrañamiento que a primera vista le producen. Habrá de pasar mucho tiempo para que ese Borges, complejo y discordante de la crónica de 1982, pueda ser aludido con plena naturalidad en, por ejemplo, un artículo del 2000 -"más bien fatigo los anaqueles de los escritores de la levedad" (2000a: 315)-. Lo mismo con la obra y figura del chileno más cercano/lejano. "Bolaño en la distancia" es un texto moroso, con una serie de parágrafos intermedios cuyo propósito, al parecer, es poner entre su literatura y la de su amigo anaqueles completos y distantes al tema -Goethe, Kafka, Gadda, Leopardi, Calvino, Biely, Nabokov- para terminar en una aporía anunciada: "Lo que son las cosas. He vuelto a acercarme a Bolaño [...]. Al escribir la primera línea de este comentario al libro de Bolaño me había propuesto ser ágil, seguir la estela de aquello que

\footnotetext{
11 Es más: en una crónica incluida en Para acabar con los números redondos, Vila-Matas parece desestimar el hecho de que Gómez de la Serna no haya llevado su extravagancia y el riesgo de una vida novelada hasta las últimas consecuencias, como sí lo lograron, entre otros, Duchamp, Kafka y Bolaño: "Durante muchísimos años Ramón, a lo largo de una serie de 'conatos de autobiografía', engañó a todo el mundo respecto al año de su nacimiento, no así la fecha, que mantuvo intacta: el 3 de julio [...]. Pero he aquí que, al escribir su autobiografía definitiva -su Automoribundia-, se arrepintió el engaño y decidió decir la verdad, lo que por otra parte no significa que necesariamente haya que creerle. En fin" (Vila-Matas 1997: 101).
} 
siempre persiguió Leopardi -me refiero a su deseo de quitar al lenguaje su peso hasta que se asemeja a la luz lunar-y sin embargo heme aquí convertido en un hombre que ha quedado enredado en el mundo de la multiplicidad de Bolaño, ese escritor que ve el mundo como un enredo, una maraña o un ovillo" (2000a: 318).

Probará en las últimas páginas de ese texto un intento más por ponerlo a distancia, comentando la estructura triádica de Los detectives salvajes, pero se adivina como una tentativa inútil. "Los detectives salvajes es, por otra parte, mi propia brecha", comenta casi en la última página: "es una novela que me ha obligado a replantearme aspectos de mi propia narrativa. Y es también una novela que me ha infundido ánimos para continuar escribiendo, incluso para rescatar lo mejor que había en mí cuando empecé a escribir" (2000a: 320).

Esa frase, que podría parecer una recurrencia al tópico de la "falsa modestia", en realidad debe asumirse como concluyente. Atraer la figura de un escritor latinoamericano para luego ponerla a distancia y reconocer que su influjo en su propia escritura o visión de la literatura es inevitable, encarna con propiedad el movimiento oscilatorio antes descrito. Esto podría hacer pensar, en última instancia, que así como ocurre con Kafka en Hijos sin hijos y Walser en Doctor Pasavento, la poderosa carga literaria de Borges, Bolaño, Aira o Monterroso obligarán a Vila-Matas a convertirse en okupa de las propuestas y temáticas de estos escritores en sus siguientes libros. No obstante, y aquí la constitución final de este nivel incluso epistemológico de su arte narrativa, creo que en caso de hacerlo deliberadamente, sus modulaciones, sus "trucos" para seguir adelante, correrían el riesgo de desvanecerse.

"Parafraseando a Ricardo Piglia", dice en una crónica de Aunque no entendamos nada, "diré que he encontrado mi vida en el interior de los textos que he leído" (2003: 48). Y ha sido en los libros de sus hermanos gemelos latinoamericanos donde mayormente se ha edificado su característico modo de pensar y escribir literatura. Latinoamérica está donde conviene a sus propósitos: en el centro profundo y líquido de su propia narrativa, sin revolucionarse demasiado pues se corre el riesgo de que el eje se desmonte de esta máquina. Latinoamérica le ha permitido trabajar estrategias o modulaciones narrativas que van desde el desplazamiento de un referente a otro hasta la demora en la reflexión metaficcional y el reforzamiento de ese singular, y aislado, lugar de enunciación en las letras españolas.

Parece suficiente para un escritor de su estatura: es sensato dejar la literatura latinoamericana ahí donde está, y no "fuera de aquí".

\section{OBRAS CITADAS}

Aira, César (2009): El congreso de literatura. México, Era.

Alazraki, Jaime (1994): Hacia Cortázar: Aproximaciones a su obra. Barcelona, Anthropos.

Bloom, Harold (2002): Cómo leer y por qué. Barcelona, Anagrama.

Della Paolera, Félix, y Cross, Esther (2007): Adolfo Bioy Casares. Sobre la escritura: conversaciones en el taller literario. Madrid, Ediciones Fuentetaja. 
Enrigue, Álvaro (2012): "Cuatro postulados sobre una máquina soltera". En Felipe Adrián Ríos Baeza (ed.): Enrique Vila-Matas: Los espejos de la ficción. México, Eón, pp. 3338.

Fresán, Rodrigo (2007): "Historia abreviada de un Vila-Matas portátil". En Margarita Heredia (ed.): Vila-Matas portátil. Un escritor ante la crítica. Barcelona, Candaya, pp. 165-167.

Palma Castro, Alejandro et. al (2012): "Enrique Vila-Matas, autor de la obra de Enrique Vila-Matas". En Felipe Adrián Ríos Baeza (ed.): Enrique Vila-Matas: Los espejos de la ficción. México, Eón, pp. 443-464.

Pitol, Sergio (2007): "Vila-Matas, premiado". En Margarita Heredia (ed.): Vila-Matas portátil. Un escritor ante la crítica. Barcelona, Candaya, pp. 172-176.

Ríos Baeza, Felipe Adrián (2012): "Vila-Matas: ese okupa literario". En Felipe Adrián Ríos Baeza (ed.): Enrique Vila-Matas: Los espejos de la ficción. México, Eón, pp. 71-92.

Sada, Daniel (2007): "El viajero más lento". En Margarita Heredia (ed.): Vila-Matas portátil. Un escritor ante la crítica. Barcelona, Candaya, pp. 93-99.

Sánchez Carbó, José (2012): La unidad y la diversidad. Teoría e historia de las colecciones de relatos integrados. Puebla, Universidad Iberoamericana.

Vila-Matas, Enrique (1997): Para acabar con los números redondos. Valencia, Pre-Textos.

- (2001): El viajero más lento. Barcelona, Anagrama.

- (2003): Aunque no entendamos nada. Santiago de Chile, J. C. Sáenz Editor.

- (2007): Exploradores del abismo. Barcelona, Anagrama.

- (2000a): Desde la ciudad nerviosa. Madrid, Alfaguara.

- (2000b): Bartleby y compañía. Barcelona, Anagrama.

- (2011): En un lugar solitario. Narrativa 1973-1984. México, DeBolsillo.

— (2013): Fuera de aquí. Conversaciones con André Gabastou. Barcelona, Galaxia Gutemberg.

_ (2017): "Sergio Pitol, mi maestro". En Centro Virtual Cervantes, <https://cvc.cervantes. es/literatura/escritores/pitol/vila_matas.htm>.

Warnken, Cristián (2002) "Entrevista con Enrique Vila-Matas". La belleza de pensar. Canal 13 Cable. Televisión. [60 minutos]. 